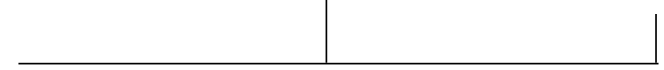

Rev. Latinoam. Psicopat. Fund., São Paulo, v. 10, n. 4, p. 653-663, dez.2007

\title{
O manejo da identificação imaginária em grupos de psicóticos*
}

\author{
Adriana Renna de Vitta \\ Paulo de Carvalho Ribeiro
}

Este artigo tem como cerne a identificação imaginária na abordagem psicanalítica de psicóticos reunidos em dispositivo de pequeno grupo. O estudo das teorias psicanalíticas no funcionamento e no manejo terapêutico dos grupos monossintomáticos forneceu o ponto de partida de nossa investigação. A especificidade da identificação na psicose e a possibilidade de estimular a criação de laços sociais entre psicóticos em pequenos grupos através do processo identificatório foi o tema principal deste trabalho.

Palavras-chave: Psicose, identificação, pequenos grupos, laço social

* O presente artigo originou-se de nossa dissertação de mestrado apresentada ao Programa de Pós-graduação em Psicologia da Universidade Federal de Minas Gerais - área de concentração em Estudos Psicanalíticos. A dissertação, intitulada A psicose e a intervenção psicanalítica nos pequenos grupos: investigações acerca da identificação e do laço social na psicose, foi defendida e aprovada em maio de 2007. 
Em "Psicologia das massas e análise do eu” (1921), Freud se empenhou em encontrar uma explicação libidinal para a organização coletiva. Nesse texto, sua principal articulação se deu em torno da idéia de que o coletivo é uma rede de indivíduos articulados verticalmente com o líder, articulação que promove o laço social, por estabelecer entre os membros de um grupo uma identificação.

Ao procurar uma explicação libidinal para a organização dos grupos, Freud encontrou mecanismos de identificação e idealização causados por um objeto exterior ao grupo: o líder. Assim, nas suas palavras "um grupo primário desse tipo é um certo número de indivíduos que colocaram um só e mesmo objeto no lugar de seu ideal do ego e, conseqüentemente, se identificaram uns com os outros em seu ego". Esta exterioridade do objeto líder é que, para Freud, determinaria a coesão de um grupo, caracterizado por uma dimensão imaginária, já que em sua origem estaria a ilusão de uma completude perdida que determina a busca de um ideal.

A igreja e o exército são, para Freud, exemplos de uma ligação particular do sujeito com um signo universal, um signo que promove a organização dos indivíduos em massa, colocados diante de um chefe. A massa seria, assim, um produto específico de uma identificação a "um único e mesmo objeto". O chefe, colocado como ideal, faz prevalecer uma ligação hipnótica entre os indivíduos, na qual não há espaço para o particular, para o singular. Esse tipo de laço não comporta a diferença subjetiva que se vê abolida em uma identificação comum. Ora, se a massa aliena o sujeito através de uma insígnia universal, um tratamento analítico a partir do dispositivo grupal deve situar-se em um lugar contrário a tal alienação, buscando a emergência da particularidade subjetiva através da presença do analista, que não dirige o grupo (esta é uma função do líder) e sim o tratamento (Laurent, 1998). É em torno dessas articulações que se organizam atualmente a prática de alguns importantes psicanalistas com grupos denominados monossintomáticos. 
No contexto atual, dominado pelas novas configurações do sintoma, tais como a anorexia, a bulimia, as toxicomanias e as depressões, vimos surgir no campo social vários agrupamentos que utilizam um traço monossintomático para se caracterizarem como um grupo. As associações de anoréxicos-bulímicos, por exemplo, utilizam, como critério de admissão nesses grupos, a insígnia identificatória constituída pelo sintoma. É em torno dessa época que se formaliza a prática da psicanálise com os grupos monossintomáticos. No momento do nascimento de instituições que convocam os sujeitos, no campo social, a partir da oferta do idêntico, de uma identificação anônima ao grupo e ao seu traço monossintomático. É o caso de grupos para alcoolistas, para pacientes que sofrem de depressão, de síndrome do pânico, de anorexia-bulimia, entre outros.

Se nesses grupos a característica sintomatológica comum tende a circular entre os componentes, reforçando sua tendência a se constituir como uma massa, Eric Laurent (1998) e Massimo Recalcati (2005) vão esclarecer, no entanto, que o trabalho do analista nesses grupos e o ponto de apoio para a direção do tratamento é, todavia, interferir em sua tendência a se perder na fusão identificatória ao "Nós”, fazendo surgir o nome próprio do sujeito. A estratégia do grupo monossintomático como um dispositivo para tratar a anorexia é, de início, acolher essa identificação, aceitando sua lógica através da oferta de tratamento. Mas esse é um movimento tático inicial, pois o trabalho do analista, em um segundo momento, será exatamente intervir naquilo que constituiu o grupo: uma identificação alienante a um significante padrão. A tarefa do analista nesses grupos é, portanto, produzir um buraco nesta identificação imaginária para que o nome próprio do sujeito possa advir. Nas palavras de Laurent (1998),

A homogeneidade do sintoma é uma ilusão. O pequeno grupo monossintomático constitui-se, na origem, sobre esta ilusão. Aquilo que dá consistência ao grupo é um laço imaginário - uma reciprocidade identificatória - que realiza uma espécie de espelhamento comum. Por isso, a direção do tratamento visa desconstruir esta identificação coletiva (...) nos grupos monossintomáticos de orientação analítica trata-se de romper a homogeneidade anônima à anorexia-bulimia para produzir o nome próprio do sujeito. (p. 265)

A partir de todas essas considerações a respeito da prática dos grupos monossintomáticos de orientação analítica, perguntamo-nos se essa teorização, baseada na idéia de que a função do analista é tentar intervir a partir da tendência do grupo em fazer massa (tendência a ele imanente), buscando a emergência da particularidade subjetiva, seria suficiente para pensarmos o trabalho com pequenos grupos de psicóticos. Algumas importantes considerações se colocam: o psicótico faz "massa”? A tendência em agrupar-se de forma monossintomática estaria presente em grupos de psicóticos? Se nos grupos monossintomáticos de orien- 
tação analítica, a principal premissa terapêutica é não reforçar a identificação e sim utilizar o grupo como tratamento da identificação, qual seria, nos grupos compostos por pacientes psicóticos, a estratégia que apontaria a direção do tratamento, se a questão inicial que se coloca a esse sujeito é exatamente a dificuldade de acesso ao social e ao simbólico, ou seja, àquilo que o faria reconhecer-se como componente de um grupo no qual se estabelecem laços sociais?

Em um grupo de psicóticos que pudemos coordenar, ${ }^{1}$ não observamos essa "reciprocidade imaginária”, essa forma de ligação que liga entre si os membros de uma coletividade, instalando o líder na posição de ideal do eu. Ao contrário, o grupo parecia funcionar sob uma constante ameaça de desintegração que precisava, a todo momento, ser trabalhada pelo analista no sentido de garantir a existência daquele espaço, a partir de sua presença atenta e constante e do desejo de que as questões trazidas por um pudessem ser compartilhadas no espaço do grupo, no espaço habitado por outros. Assim, não havia naquele grupo uma tendência dos componentes em agrupar-se de forma monossintomática, agrupamento que leva em consideração a busca fantasiosa por um objeto que viria suplantar a falta. Se Lacan (1964) nos lembra que o sujeito neurótico busca articular sua falta com aquilo que falta ao Outro, através do fantasma, ele nos esclarece também que o psicótico não dispõe desse recurso, que só poderia ser alcançado após a metáfora paterna.

Se ao sujeito psicótico não foi possível o acesso às identificações simbólicas, vetadas pela forclusão do Nome-do-Pai, não podemos pensar, então, num ideal do eu em torno do qual se articulam os grupos. Preso à relação em espelho, o psicótico encontra-se impossibilitado de operar uma identificação onde "um só e mesmo objeto é colocado no lugar de seu ideal do eu”, como os integrantes de um grupo fariam com o líder e, conseqüentemente, impossibilitado também de identificar-se horizontalmente em um grupo, do modo descrito por Freud. Nesse sentido, como podemos pensar uma organização coletiva sem esse elemento exterior a determiná-la, caracterizado pelo líder? E assim, resta-nos ainda que nos perguntemos: como se daria a intervenção do psicanalista em um grupo de psicóticos, buscando um tratamento possível dos sujeitos envolvidos ali? O psicótico faz grupo?

Sabemos que por sua especificidade estrutural, o psicótico resiste ao grupo, marcado por uma relação muito particular com a linguagem, relação que o deixa

1. Esse grupo com o qual pudemos trabalhar e que se constituiu como objeto de nossa pesquisa, surgiu dentro de um hospital-dia psiquiátrico no qual exercíamos a função de coordenação. Esse "grupo de conversa”, nome dado pelos pacientes, tinha a intenção de trabalhar com pacientes que freqüentavam a instituição, utilizando-se exclusivamente da fala como recurso terapêutico. 
"fora do discurso" e, por isso, distante do sentido compartilhado em uma dada comunidade. $\mathrm{O}$ estabelecimento de vínculos sociais encontra, neste aspecto, um grande obstáculo, pois estar "fora do discurso" é estar fora de um conjunto significante capaz de habilitá-lo a um vínculo com o outro e, portanto, de ligá-lo a esse outro. Aliás, o significante "desligado” parece sempre rondar esse sujeito, aspecto razoavelmente fácil de observar no cotidiano da clínica, tanto nas experiências dissociativas quanto na experiência paranóica: desligado do outro, desligado de si mesmo, desligado de seus pensamentos, desligado de seu corpo, desligado do sentido. Por isso é que o tratamento psicanalítico de sujeitos psicóticos deve levar em conta a invenção de recursos que possam possibilitar minimamente a sua ligação com o outro, na expectativa da construção de um laço que leva em consideração a construção de respostas pelo sujeito psicótico para aquilo que o invade.

Deste modo, entendemos que não seria possível adotar com sujeitos psicóticos a lógica que norteia o trabalho psicanalítico com os grupos monossintomáticos, a saber, a desidentificação, já que esses grupos originam-se a partir de uma lógica alienante própria, aspecto que fornece sua consistência e sua unificação. Se os indivíduos, em grupos de neuróticos, tendem a fazer massa, o dispositivo do pequeno grupo monossintomático é uma modalidade de tratamento desta inclinação à identificação de massa. Ora, o psicótico faz massa? Em um grupo monossintomático, o elemento universal e aquilo que dá consistência ao grupo é a identificação, o reconhecimento recíproco entre os membros de um grupo de um laço identificatório imaginário. Isso é precisamente o que não está presente, a priori, em grupos de psicóticos.

Partimos então do pressuposto de que se adotássemos a inversão dessa lógica que ordena o trabalho nos grupos monossintomáticos, talvez pudéssemos encontrar um caminho mais promissor. Lacan (1955-1956), no seminário As psicoses, nos ensina que a relação em espelho provoca uma "dissolução do outro como identidade” (p. 115), caracterizando um desarranjo no plano imaginário e, conseqüentemente, uma desarticulação nas relações com o semelhante. A conseqüência desta “dissolução do outro como identidade” é uma redução da estrutura imaginária, despida em seu caráter mortal, onde observamos a proliferação de fenômenos duais de agressividade, de transitivismo e mesmo de despersonalização. Jacques-Alain Miller no texto "Suplemento topológico a 'uma questão preliminar'” (1996), nos esclarece ainda que a forclusão do Nome-doPai não deve ser entendida sem a conjugação de um importante processo que a acompanha, a saber, “... a regressão tópica ao estádio do espelho. A forclusão revelada como falha na estrutura simbólica ressoa sobre a estrutura imaginária, ela a dissolve, a conduz à estrutura elementar chamada estádio do espelho” (p. 122-3). 
Haveria, portanto, um uso possível de um grupo pelo sujeito psicótico? Ora, se o psicótico não faz grupo, se ele não realiza, como no caso de grupos de anoréxicos, uma identificação idealizada a um significante padrão - ilusão que assegura a consistência do grupo - podemos pensar, no entanto, que ele pode se servir da estruturação lógica do grupo e, portanto, da estruturação lógica do laço social, amparada pela identificação e pela idealização.

Nesse sentido, a identificação imaginária, aquela realizada com o semelhante, com o "outro identidade”, no registro do eu-ideal e que se dá pela via da imitação, revelou-se uma saída possível ao sujeito psicótico inserido no dispositivo grupo, ainda que precária e frágil. Pensar a direção do tratamento na psicose a partir da via da alienação, da busca pela imagem que gostaríamos de ter, é introduzir o psicótico na dimensão de uma identificação possível, possibilitando a invenção de um pequeno ponto de basta e, portanto, é introduzir também uma mediação possível entre o sujeito e o outro.

Desse modo, se em grupos monossintomáticos de orientação analítica se pretenderia um tratamento da identificação, em grupos de psicóticos se pretenderia um tratamento pela identificação. A direção do tratamento em grupos de psicóticos passaria, então, pela produção de identificações imaginárias, pela produção de laços identificatórios comuns capazes de produzirem uma nomeação ao sujeito e, por isso, uma certa inscrição na organização social que acontece à sua volta. Sabemos, contudo, que não é possível considerar a identificação imaginária sem pressupormos um outro processo que lhe dá sustentação, a saber, o estádio do espelho. Na experiência do espelho, ao mesmo tempo em que se forja uma imagem que funciona como ortopedia egóica, forma-se também o germe da alienação imaginária. Em outras palavras, a função imaginária, na psicose, necessita de um tratamento pelo simbólico, pois de outro modo, fica reduzida ao espelho. Assim, em um tratamento pela identificação, não se trata de estruturarse em ligações duais, sustentando-se a presença terceira do simbólico pelo grupo. O fragmento clínico que passaremos a descrever serve ao propósito de expor um uso possível de um grupo por um sujeito psicótico, uso que proporcionou a esse paciente importantes efeitos terapêuticos.

\section{O uso de um grupo por um psicótico}

O grupo com o qual pudemos trabalhar em uma clínica psiquiátrica de Belo Horizonte tornou-se um lugar privilegiado de endereçamento das questões dos pacientes que dele participavam, tanto os inseridos no hospital-dia quanto os que se encontravam internados na clínica temporariamente. O grupo se reunia uma 
vez por semana, com um número de integrantes variando entre quatro e oito pessoas. Os pacientes eram convidados a participar a partir de dois critérios. O primeiro deles consistia em observar a indicação dos profissionais responsáveis por cada caso e, o segundo, era simplesmente acolher o desejo de cada um. Assim, a partir do convite, a participação no grupo levava em conta a concordância do terapeuta assistente e o desejo da cada um em fazer parte.

Esse grupo de conversa, nome dado pelos pacientes do hospital-dia, surgiu neste contexto de atendimento, a partir de um pedido dos próprios pacientes, que necessitavam de um espaço onde pudessem falar mais de si. As reuniões gerais, destinadas à organização do hospital-dia e da rotina da instituição (revisão do quadro de atividades e oficinas da semana, organização de passeios, avaliação da participação de cada um, entre outras questões) não comportavam adequadamente as inúmeras queixas e pedidos individuais, já que essas reuniões possuíam um caráter mais administrativo e voltado para o funcionamento diário da clínica.

Constituímos, então, dentro do quadro de atividades do hospital-dia, um grupo que se utilizava exclusivamente da fala como recurso terapêutico e, por esse motivo, apresentava-se como uma nova possibilidade de trabalho, essencialmente diferente das atividades desenvolvidas nas oficinas de pintura, cerâmica, letras e outras, comumente utilizadas nos serviços atuais de atendimento à saúde mental.

Não sem demora, foi possível constatar que coordenar um grupo de psicóticos exigia do analista um certo desprendimento no que se refere a um setting ideal. Em alguns encontros os pacientes apresentavam-se desagregados, excessivamente persecutórios e inquietos. Em outros, eles simplesmente saíam da sala durante a sessão, retornando alguns minutos depois ou mesmo deixando de retornar. De qualquer forma, havia um nítido interesse em "esperar o dia do grupo" para "falar uma coisa particular”, fenômeno que se refletiu na rotina da instituição, quando, por exemplo, as palavras começaram a aparecer no lugar dos atos. Pacientes que eram agressivos ou excessivamente arredios ou que apresentavam comportamentos erotizados no contato com algum membro da equipe e com outros pacientes, puderam encontrar, no grupo, um espaço de trabalho para essas questões e para outras que freqüentemente apareciam no cotidiano da instituição.

Em uma ocasião, esse grupo que já se mantinha estável com um número fixo de participantes há vários encontros, sofreu algumas alterações em sua dinâmica a partir da entrada de uma nova paciente. Nesse encontro os pacientes falavam das internações que já haviam sofrido ao longo da vida, internações relacionadas à história psiquiátrica de cada um. Um paciente, naquele dia mais desorganizado, que chamarei aqui de Joel, não acompanhava a discussão, falando em um tom mais alto, levantando-se muitas vezes e, por isso, dispersando o grupo. Sua 
atitude causava um certo incômodo nos participantes que se olhavam entre si fazendo sinais negativos com a cabeça. Com um diagnóstico de esquizofrenia hebefrênica, Joel, à época com 45 anos, freqüentava o grupo de um modo muito próprio, às vezes um pouco inadequado e agitado, outras vezes exibindo um pensamento desconexo, com fuga de idéias e desagregação. Até então, não havia feito um laço consistente com o grupo.

A paciente, que nunca havia estado naquele grupo, fazia alguns comentários sobre cada um dos participantes, lembrando-se de alguns, buscando referências em outros, até que, em um determinado momento, visivelmente incomodada com a inadequação de Joel, ela se referiu enfaticamente a ele, "exigindo" que ele se fizesse entender, movimento que o grupo já havia esboçado sem muito êxito. Como Joel falava de forma pouco inteligível, sem se preocupar ou sem conseguir acompanhar as discussões no grupo, a paciente propôs que ele definisse então seus males em apenas duas palavras, pensando que assim conseguiria entendêlo. Joel, para surpresa do grupo, entende a proposta e diz: "é para cada um falar da sua doença e da carga que carrega? Então tá, pode começar que eu vou te ajudar”. Os pacientes então começam a expressar-se de forma mais sucinta, cada um se definindo a partir de seus males e de expressões médicas com as quais já haviam entrado em contato: "estresse e fadiga", "oscilação de humor", "tenho depressão", "sou PMD”, entre outros, até que Joel se pronuncia, fazendo-se finalmente entender pelo grupo: "meu problema é com a minha família que não sai do meu pé por causa das drogas do tráfico. Então deve ser isso: 'problema com drogas'."

É importante esclarecermos que Joel já havia feito uso de drogas na adolescência, período que coincidiu com o desencadeamento de sua psicose, mas esse uso, que cessou após esse período, não preenchia os critérios para uma dependência química, fato corroborado por seus médicos e por seus familiares.

A partir de sua participação nesse encontro, Joel parece ter construído um primeiro significante capaz de articulá-lo com aquele grupo, pois ao concluir "meu problema é a droga", ele tenta, a partir do significante droga, construir um laço social. A droga, em lugar de excluí-lo, o inseria em um discurso social, fornecendo-lhe um nome no qual podia se referenciar para se dirigir ao outro. Apesar de não participar de todas as sessões, Joel passa a se interessar um pouco mais pelas pessoas que freqüentavam o grupo e a se nomear "dependente de drogas" a todos aqueles que o interpelavam pelo fato de freqüentar a instituição: "eu sou dependente de drogas, por isso estou aqui com vocês". A partir desse momento, este paciente se viu, ainda que precariamente, fazendo parte de um grupo. Curiosamente a paciente que havia proposto o jogo, ao se definir como "PMD", também se acalmou com a palavra apropriada e sintética do Outro- 
instituição. Ao acolher essa forma mais sucinta de expressão, Joel, nesse encontro, apazigua-se no contato com o outro, assim como os outros pacientes que, ao sintetizarem seu mal a partir de expressões médicas já ouvidas e até então vazias de sentido, reduziram ao mínimo, na linguagem, aquilo que poderia defini-los.

A partir desse fragmento clínico, acreditamos ser possível demonstrar que a identificação, fenômeno que pode ser considerado um operador clínico fundamental no trabalho com grupos, demanda, no caso da psicose, um entendimento de sua especificidade para que ela possa adquirir um valor terapêutico. Entendemos, a partir dos importantes resultados terapêuticos observados nos pacientes inseridos no grupo que coordenamos, que a via imaginária, amparada pela circulação simbólica a que o dispositivo grupo se propõe, já que se encontra ancorado na perspectiva do laço social e da palavra, revelou-se possibilitadora de um novo arranjo desses sujeitos com o outro, permitindo novas saídas que alcançaram efeitos estabilizadores em alguns dos participantes do grupo. Nesse sentido, entendemos que o grupo pode ser considerado um instrumento de mediação entre o sujeito e o mundo das representações, um artefato que pode promover a passagem da imagem ao símbolo de forma amortecida, um filtro de construção da realidade e, desse modo, contribuir para a instituição de um outro social menos persecutório e ameaçador.

Nossa proposta de trabalho com um grupo de psicóticos buscou levar em consideração todos esses aspectos teóricos e clínicos, buscando contemplar o desafio lacaniano “de não recuar diante das psicoses” e por isso, sempre inventar, pela via da própria clínica, novos dispositivos amparados pelos princípios da psicanálise. Partindo desses mesmos princípios, é possível dizer que se o psicótico resiste a essa organização específica chamada grupo, nada impede, entretanto, que exista um uso possível de cada grupo por cada sujeito psicótico, uso que pode proporcionar um certo rearranjo em sua relação com o outro. A partir da idéia de que um psicótico pode se servir da estruturação lógica do laço social sem necessariamente estar inserido nele, este trabalho buscou trazer uma contribuição ao tratamento desses sujeitos, tratamento onde a reinvenção e a revisão dos procedimentos utilizados é sempre necessária.

\title{
Agradecimentos
}

\author{
À Casa Freud
}




\section{Referências}

Freud, Sigmund (1921). Psicologia das massas e análise do eu. In: Edição Standard Brasileira das Obras Psicológicas Completas de Sigmund Freud. Rio de Janeiro: Imago, 1996. v. XVIII.

Lacan, Jacques (1949). O estádio do espelho como formador da função do eu. In: Escritos. Rio de Janeiro: Jorge Zahar, 1998. p. 96-103.

(1955-1956). O seminário. Livro 3. As psicoses. Rio de Janeiro: Jorge Zahar, 1988.

(1964). O seminário. Livro 11. Os quatro conceitos fundamentais da psicanálise. Rio de Janeiro: Jorge Zahar, 1998.

LAURENT, Eric (resp.). A função do pequeno grupo na lógica da psicanálise. Relatório das Escolas da Associação Mundial de Psicanálise (AMP), École Européene de Psychanalyse, p. 257-285, 1998.

MilLeR, J. A. Suplemento topológico a “uma questão preliminar”. In: Matemas I. Tradução Sérgio Laia. Rio de Janeiro: Jorge Zahar, 1996.

ReCALCATI, Massimo. Lignes pour une clinique des monosymptômes: anorexie, boulimie, dépression, attaquepanique. La Cause Freudiene, Paris, Navarin, n. 61, p. 83-98, nov. 2005.

\section{Resumos}

Este artículo tiene como núcleo central la identificación imaginaria en el abordaje psicoanalítico de psicóticos reunidos en pequeños grupos. El estudio de las teorías psicoanalíticas en el funcionamiento y en el manejo terapéutico de los grupos monosintomáticos forneció el punto de partida de nuestra investigación. La especificidad de la identificación en la psicosis y la posibilidad de estimular la creación de lazos sociales entre los psicóticos en pequeños grupos a través del proceso de identificación fue el tema principal de este trabajo.

Palabras claves: Psicosis, identificación, pequeños grupos, lazo social

Cet article porte sur l'identification imaginaire dans l'approche psychanalytique des patients psychotiques qui participent à des petits groupes thérapeutiques. Notre point de départ est l'étude des théories psychanalytiques sur les groupes monosymptomatiques. Les aspects particuliers de l'identification dans la psychose et la possibilité de l'employer comme facteur de promotion de liens sociaux chez les psychotiques constituent le point central de nos élaborations.

Mots clés: Psychose, identification, petits groupes, lien social 
One of the main topics of the study described in this article is the role played by imaginary identification in the psychoanalytical approach to psychotics treated together in small groups. The study of psychoanalytic theories on group functioning and the therapeutic handling of mono-symptomatic groups provided the starting point for our inquires. The specificity of identification in psychotics and the possibility of improving the establishment of social ties among the members of such groups through identification processes was the focus of the main part of our work.

Key words: Psychosis, identification, small groups, social ties

\section{Adriana Renna de Vitta}

Psicóloga; psicanalista; mestre em Psicologia pela Universidade Federal de Minas Gerais (Belo Horizonte, MG, Brasil) - área de concentração em Estudos Psicanalíticos.

Rua Coronel Melquíades Horta, 54 - Castelo

30810-595 Belo Horizonte, MG Brasil

e-mail: adrianavitta@terra.com.br

\section{Paulo de Carvalho Ribeiro}

Psicanalista; doutor em psicanálise pela Universidade Paris VII (Paris, França); professor do Programa de Pós-graduação em Psicologia da Universidade Federal de Minas Gerais (Belo Horizonte, MG, Brasil).

Rua Bambuí, 25/1600

30210-490 Belo Horizonte, MG, Brasil

Fone: (31) 3282-7082

e-mail: icaro.bhz@terra.com.br 